\title{
Monitoring and Control System for Heat Experimental Equipment of High-Speed Vertical Spindle Bearings
}

\author{
Giang-Nam Le*, Xuan-Hieu Ngo, Dinh-Quy Pham, Vinh-Hai Nguyen \\ Hanoi University of Science and Technology, Hanoi, Vietnam \\ *Email: nam.legiang@hust.edu.vn
}

\begin{abstract}
High speed of spindle for high-speed machining is the mission and development trend of today's machine tools. However, improper lubrication can cause a large temperature difference on the bearings, causing thermal deformation that affects the accuracy of the spindle. Heat experimental equipment for high-speed vertical spindle bearing is necessary. This paper presents a design and manufacture of control and monitoring system of heat experimental equipment for high-speed vertical spindle bearing based on PLC, WinCC and Webserver. This experimental device with supervisory control solution allows easy implementation of the test mode and data collection to plan out the appropriate lubrication mode. The system includes motor control and monitoring, observing of sensors, alarm and reporting at local and on site remotely. This solution can be applied to other industrial equipment to meet the needs of Industry 4.0.
\end{abstract}

Keywords: Vertical spindle, bearing heat, experimental equipment, control and monitoring.

\section{Introduction}

The heat generated in spindle bearings should be taken seriously. Some studies have implemented by simulation $[1,2]$ or theoretical and experimental analysis [3] to evaluate the influence of heat on the structure of the spindle as well as the solutions of oilair lubrication [4] to maintain a stable temperature of spindle bearing to avoid thermal deformation and ensure machine tool spindle accuracy. However, the experimental equipment for lubricating mode for high-speed vertical spindle bearings, as well as the control solution for automatic monitoring of experimental mode and data collecting for planning to discover an appropriate lubrication regime, have yet to be provided.

In addition, supervisory control is currently accomplished using microcontrollers, PLCs, and other similar devices. PLCs, on the other hand, have shown to be more stable, accurate, and easy to replace and maintain. As a result, the research will use a Siemens S7-1200 PLC to create a control and monitoring system for the spindle thermal experimental system.

Using a spindle bearing thermal testing equipment with numerous test speeds and varied oilair modes and lubricants, heat generated by friction in the bearings spindle over time is collected, monitored, and alerted. The configuration of an automatic monitoring control system based on PLC, WinCC, and Webserver are presented in this study.

ISSN: $2734-9373$

https://doi.org/10.51316/jst.152.ssad.2021.31.2.8

Received: September 9, 2020; accepted: January 12, 2021
The system includes power source control and monitoring, sensor monitoring, alarm and export reports locally as well as remotely.

\section{Mechanical Structure of Experimental Device}

To study the heat transfer in the spindle, this research used a commercial vertical spindle MAC-V0 as shown in Fig. 1a by Takisawa. The spindle has a vertical construction, consisting of 4 angular contact ball bearings NSK 7010A.

To supply air-oil to lubricate the main bearings during operation and experimentation, Giang-Nam et al [4] have designed a lubrication unit (Fig. 1.d), that is formed from standard elements for medium-sized vertical spindle with 4 angular contact ball bearings, and includes the following elements: mixing valve MV204-100-AAAA0000, four oil nozzles - 169-000$101+\mathrm{xxx}$ (VP1 4), oil pump - MKU2-12BC11000 +428 that integrated $3 \mathrm{~L}$ oil tank and oil filter, air compressor - TW-OF550-25L, air filter with built-in water separator - 231-900-028.U1, pressure valve. Air flow and oil flow are quantified by standard screw (Fig. 2), air pressure, inlet oil is set by pressure valve. Pump cycle is custom controlled. Air source on/off is controlled according to the operating mode. Lubricants recommended for use in grades ISO VG 32 to VG 100 [3] are directly supplied from " $3 \mathrm{~L}$ oil tank".

Heat generated during operation is concentrated mainly in the bearings [1], heat transfer to the spindle housing and convection with cooling compressed air is continuously fed into the bearing cavity along with lubricating oil. 


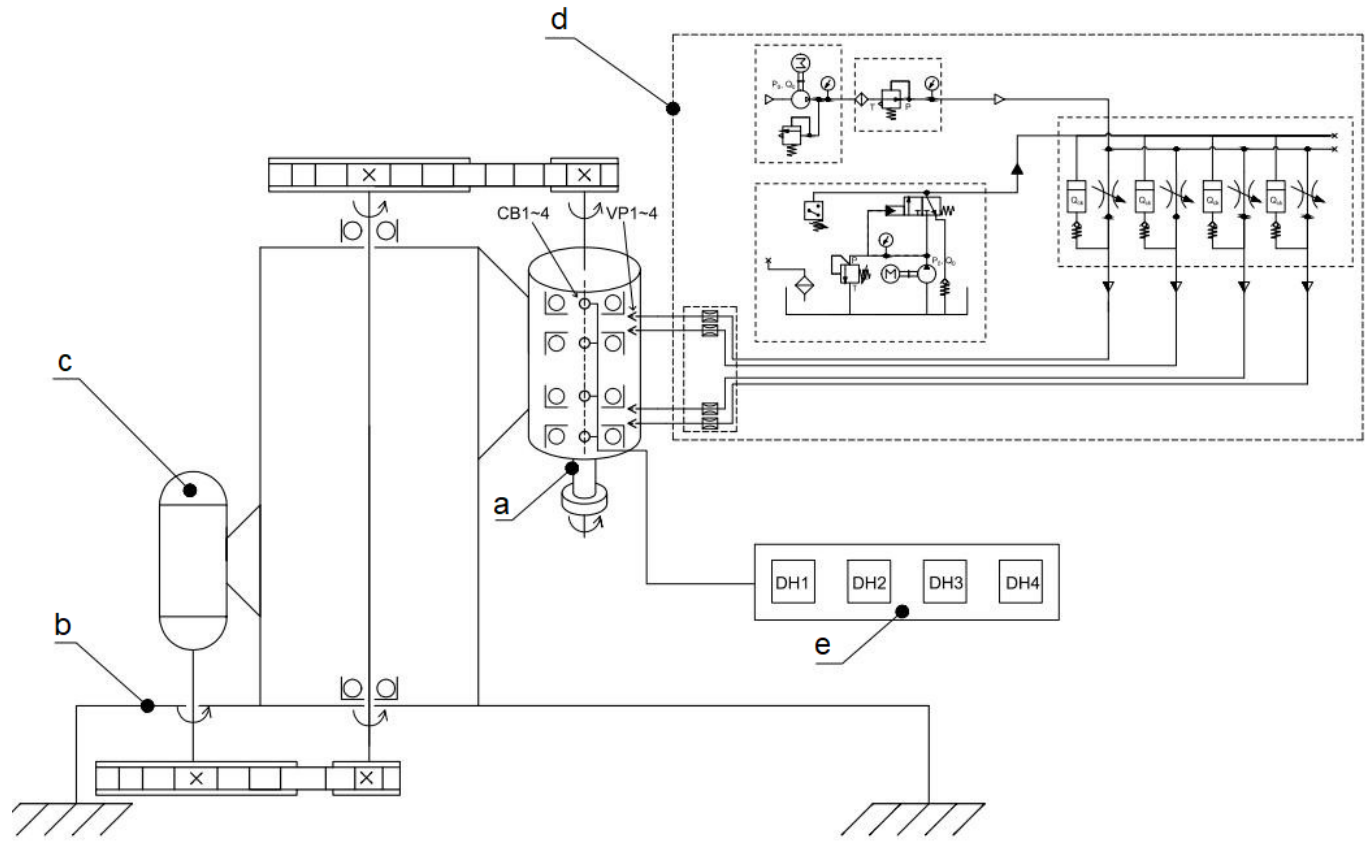

(a). Takisawa's MAC-V0 experimental spindle with oil-air lubrication solution; (b). Mechanical frame; (c). Stepless transmission upto 32000 rpm; (d). Air supply - lubricating oil for four NSK 7010 A bearings through 4 nozzles VP1 4; (e). The device displays and measures temperature from 4 sensors CB1 4

Fig. 1. Heat experimental device for high-speed vertical spindle bearings.

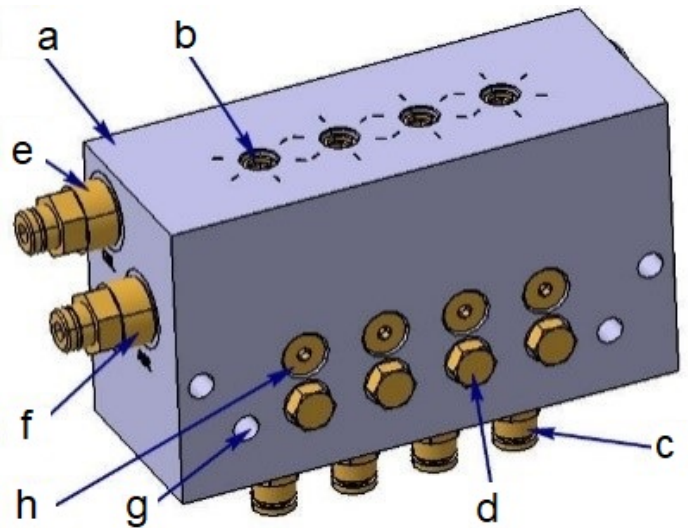

a. Block; b. Air flow adjustment screw; c. Output of oil - air; d. Port for mounting pressure gauge; e. Oil inlet; f. Air inlet; g. Assembly hole; h. Technological hole

Fig. 2. Structure of oil - air mixing valve

Therefore, temperature sensors, $\mathrm{CB} 1 \sim 4$ are located at the outer ring positions of the bearings.

The spindle is stepless controlled from 0 to 32000 (rpm) to simulate the working mode of the machine tool. The transmission consists of a Fanuc $\alpha 1.5$ motor servor (Fig. 1.c) that has speed range from 0 to 8000 (rpm), the power of $3.7 \mathrm{Kw}$ and two pulley toothed belt transmissions with a total gear ratio of $1-4$. The whole system is supported by a mechanical frame (Fig. 1.b).

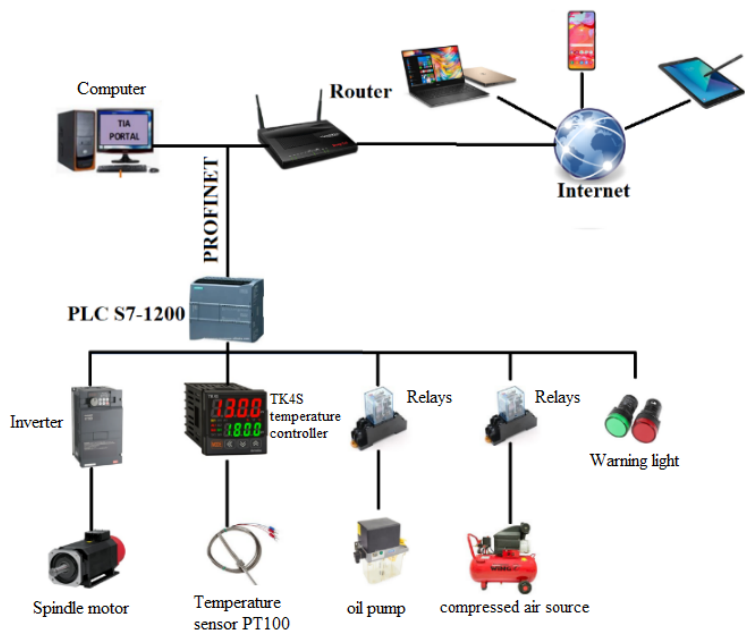

Fig. 3. Structure of local and remote device control and monitoring system via internet

\section{Control and Monitoring System}

From the requirements of the actuator and measurement as described in section 2, the system needs to control a servor motor for stepless transmission of the spindle speed, control of the oil source and compressed air, collection and display the sensor values as well as perform overheat warnings, lubricating oil readiness for bearings operation and working speed with the schematic diagram as shown in Fig. 3. 
Table 1. Control and monitoring equipment

\begin{tabular}{|c|c|c|}
\hline Device & Code & Description \\
\hline Inverter & $\begin{array}{l}\text { Fr- } \\
\text { A720- } \\
7.5 \mathrm{KW}\end{array}$ & $\begin{array}{l}\text { Wattage } 7.5 \mathrm{Kw} \text {. } \\
\text { There is support for } \\
\text { Modbus-RTU } \\
\text { communication. }\end{array}$ \\
\hline $\begin{array}{l}\text { Temperature } \\
\text { sensor }\end{array}$ & $\begin{array}{l}\text { RT- } \\
\text { M06- } \\
\text { L050- } \\
\text { K01 }\end{array}$ & $\begin{array}{l}\text { Rod sensor is suitable } \\
\text { for plug-in the hole } \\
\text { for direct } \\
\text { measurement of } \\
\text { bearing temperature }\end{array}$ \\
\hline $\begin{array}{l}\text { Autonics } \\
\text { Temperature } \\
\text { Controller }\end{array}$ & $\begin{array}{l}\text { TK4S- } \\
\text { T4SN }\end{array}$ & $\begin{array}{l}\text { Self-process the } \\
\text { signal from the } \\
\text { sensor and display } \\
\text { the temperature with } \\
\text { tolerance } \pm 0,3 \% \text {. } \\
\text { There is support for } \\
\text { Modbus-RTU } \\
\text { communication. }\end{array}$ \\
\hline Relays & $\begin{array}{l}\text { Omron } \\
\text { MY4N }\end{array}$ & $\begin{array}{l}\text { Control voltage relay } \\
24 \mathrm{~V}, \quad \text { switching } \\
\text { voltage } 220 \mathrm{~V} \text { for oil } \\
\text { pump } \\
\text { compressed air. }\end{array}$ \\
\hline $\begin{array}{l}\text { PLC and } \\
\text { communication } \\
\text { module }\end{array}$ & $\begin{array}{l}\text { PLC S7- } \\
1200 \\
\text { Module } \\
\text { CB1241 }\end{array}$ & $\begin{array}{l}\text { Transmission, } \\
\text { retrieval and } \\
\text { processing signal. } \\
\text { Support webserver } \\
\text { and profilnet } \\
\text { communication } \\
\text { protocol. }\end{array}$ \\
\hline
\end{tabular}

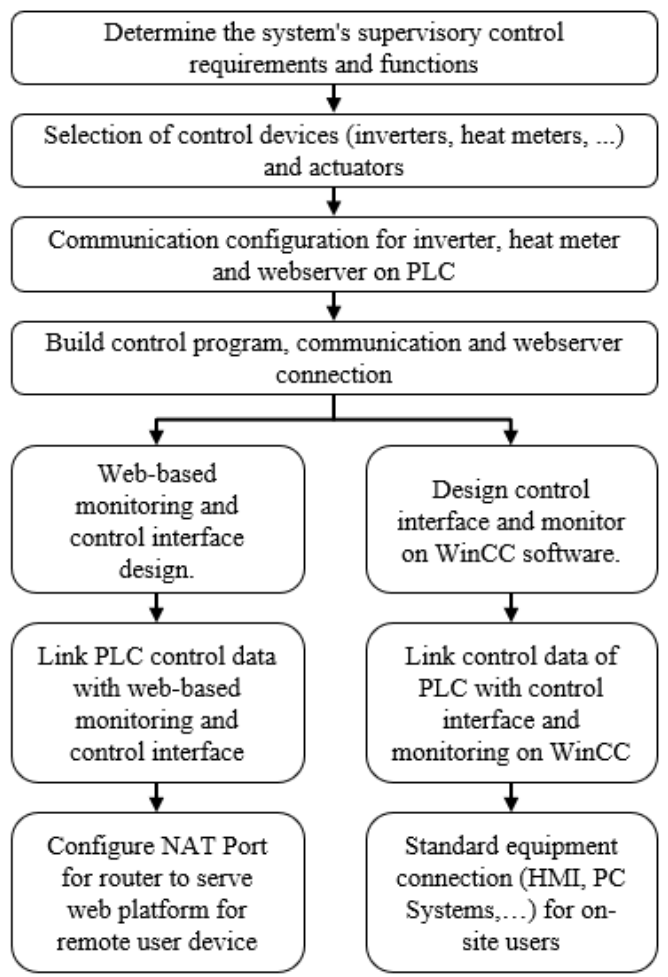

Fig. 4. The process of building the control and monitoring system
Table 2. Communication parameters for inverter

\begin{tabular}{|c|c|c|c|}
\hline Parameter & Name & Description & Value \\
\hline Pr.331 & Comm Address & $\begin{array}{l}\text { Station number } \\
\text { of the inverter, } \\
\text { each device } \\
\text { needs a } \\
\text { separate } \\
\text { address to } \\
\text { distinguish it } \\
\text { from other } \\
\text { connected } \\
\text { devices }\end{array}$ & 05 \\
\hline Pr.332 & Comm_Speed & $\begin{array}{l}\text { Select } \\
\text { transmission } \\
\text { speed }\end{array}$ & 19200 \\
\hline Pr.333 & $\begin{array}{l}\text { Comm_parity } \\
\text { bit }\end{array}$ & $\begin{array}{l}\text { Select stop bit } \\
\text { length }\end{array}$ & 1 \\
\hline Pr.334 & $\begin{array}{l}\text { Comm_Stop } \\
\text { bit }\end{array}$ & $\begin{array}{l}\text { Option to } \\
\text { check parity }\end{array}$ & 2 \\
\hline Pr.335 & $\begin{array}{l}\text { Comm_respon } \\
\text { se waitting } \\
\text { time }\end{array}$ & $\begin{array}{l}\text { Set data } \\
\text { transmission } \\
\text { time for } \\
\text { inverter and } \\
\text { response } \\
\end{array}$ & 10 \\
\hline Pr.549 & $\begin{array}{l}\text { Potocol } \\
\text { selection }\end{array}$ & $\begin{array}{l}\text { Select a } \\
\text { communication } \\
\text { method. } 0 \\
\text { Computer link } \\
\text { inverter } \\
\text { protocol }\end{array}$ & \\
\hline
\end{tabular}

Table 3. Communication parameters of Autonics temperature controller

\begin{tabular}{|l|l|l|l|}
\hline Parameter & \multicolumn{1}{|c|}{ Name } & \multicolumn{1}{|c|}{ Description } & \multicolumn{1}{|c|}{ Value } \\
\hline Pr.4_Adrs & Comm_Address & $\begin{array}{l}\text { Clock station } \\
\text { number, each } \\
\text { clock will set } \\
\text { a different } \\
\text { address }\end{array}$ & $\begin{array}{l}\text { Respectivel } \\
\text { y for 4 } \\
\text { Autonics } \\
\text { temperature } \\
\text { controller is } \\
1,2,3,4\end{array}$ \\
\hline Pr.4_bPs & Comm_Speed & $\begin{array}{l}\text { Select } \\
\text { transmission } \\
\text { speed }\end{array}$ & 19200 \\
\hline Pr.4_Prty & $\begin{array}{l}\text { Comm_parity } \\
\text { bit }\end{array}$ & $\begin{array}{l}\text { Select stop bit } \\
\text { length }\end{array}$ & 1 \\
\hline Pr.4_Stp & Comm_Stop bit & $\begin{array}{l}\text { Option to } \\
\text { check parity }\end{array}$ & Even \\
\hline Pr.4_Rswt & $\begin{array}{l}\text { Comm_response } \\
\text { waitting time }\end{array}$ & $\begin{array}{l}\text { Set data } \\
\text { transmission } \\
\text { time for } \\
\text { inverter and } \\
\text { response }\end{array}$ & 10 \\
\hline
\end{tabular}

Working spindle speed is controlled by inverter. Exchange control data from PLC with inverter via MODBUS RTU industrial communication protocols to perform control and monitoring. Oil pump, compressed air source are controlled by relays. The working temperature at the spindle shaft bearings is measured and monitored by PT100 sensors ranging 
from $0{ }^{\circ} \mathrm{C}$ to $600{ }^{\circ} \mathrm{C}$. Value displayed directly on the heat meter TK4S-T4SN. Also, via the MODBUS RTU communication protocol, the PLC can access these temperature values on the registers of the heat meters. The equipment is selected and described as in Table 1. In which, the communication parameters for the inverter are set up as in Table 2, and the

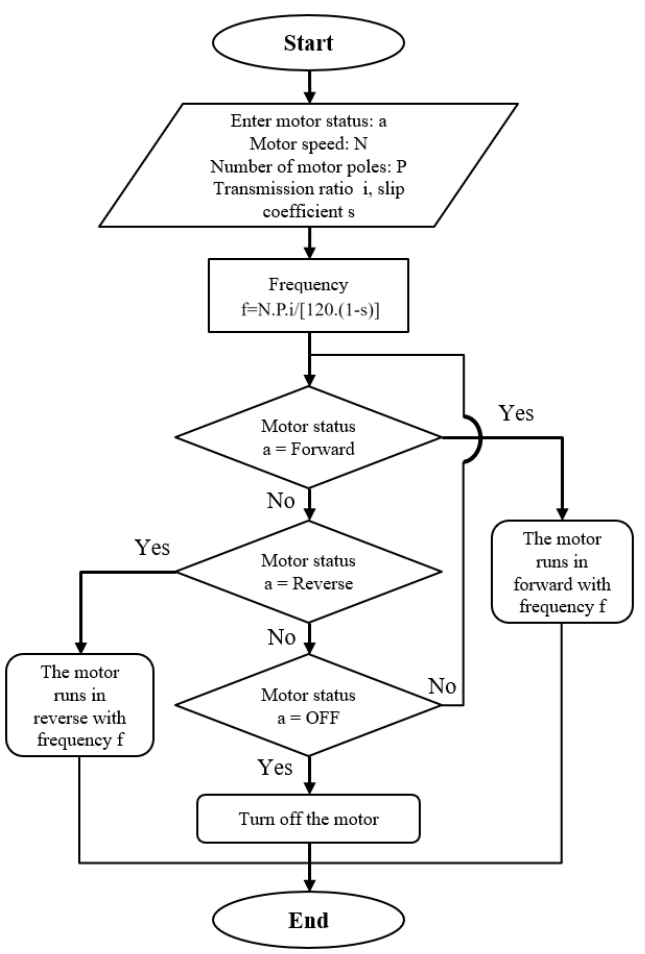

(a). Motor speed control

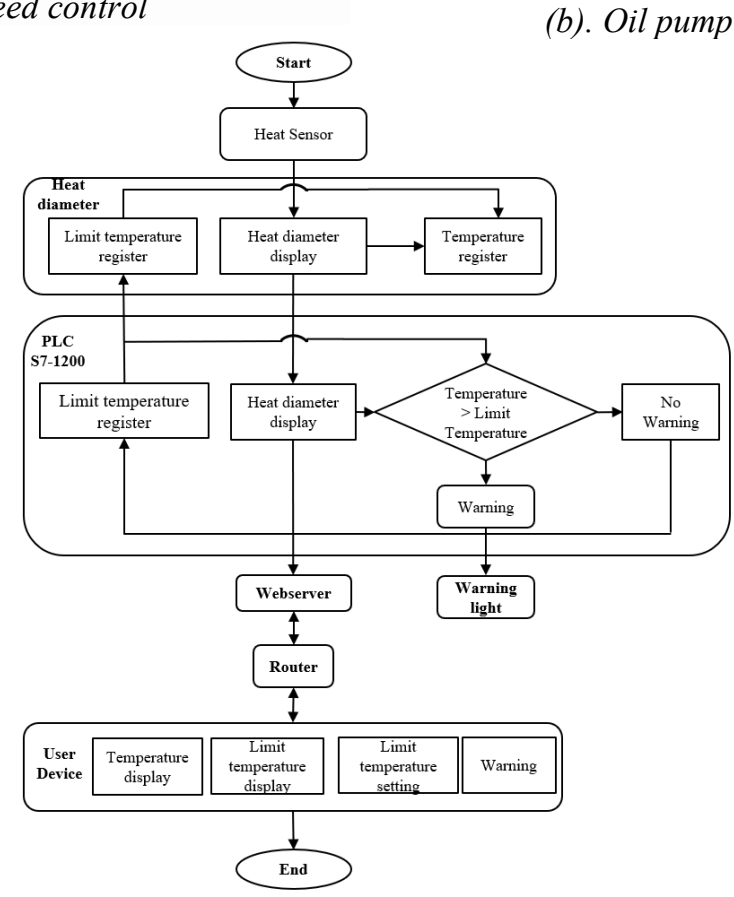

(c). Monitoring and control of temperature

Fig. 5. Algorithm diagram, control and monitoring communication parameters for the heat meter are set up as in Table 3.

From the principal diagram (Fig. 3), with the calculated and selected equipment, the process of building a local and remote control and monitoring system is set up as shown in Fig. 4.

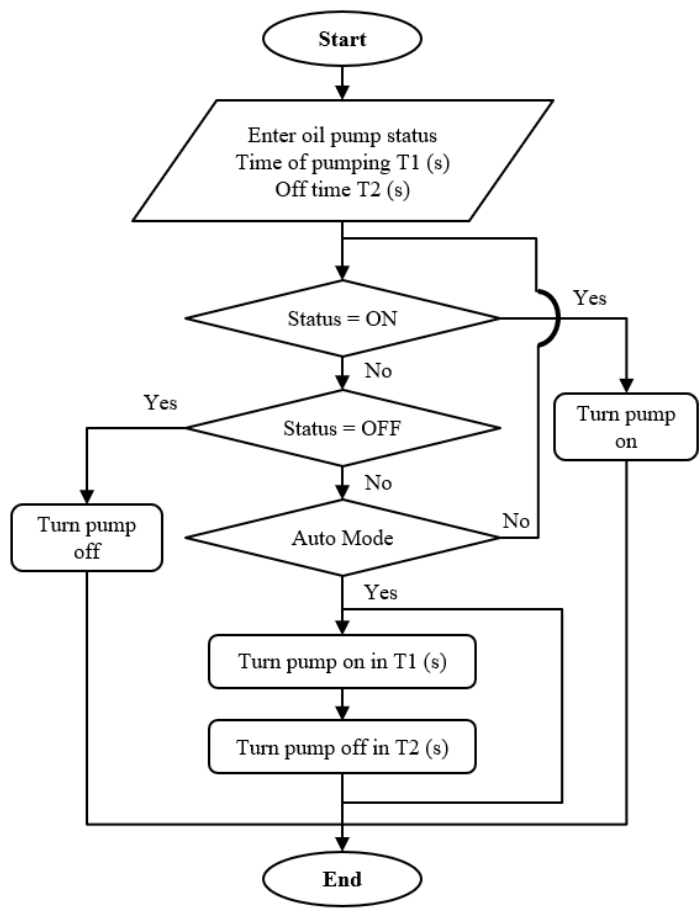

(b). Oil pump control and cycle 
In this study, the heat experimental equipment's control and monitoring system for spindle bearing is used Siemens PLC S7-1200 [5], a device that combines great stability and precision with robust communication capabilities. Webserver [6] is one of the PLC S7-1200's notable features. The profinet communication port on the PLC S7-1200 is built-in. Webserver enables access to the system at any time and from any location, as well as control and monitoring the system from a computer or mobile device with network connectivity.

The Fig. 5 is the structure of the entire system for local and remote control and monitoring: Equipment, engines, inverters, thermal sensors, thermal clocks, oil pumps, pneumatic sources, relays, and warning lights are all controlled by the PLC S71200. On the computer is installed TIA PORTAL software that is used to program PLC S7-1200 and Software Visual Studio Code for web programming, The web interface is connected to the PLC S7-1200 through router with an internet connection. A web browser can be used to access the system from devices such as PCs, cellphones, tablets, and mobile devices. The process is as shown in Fig. 4, the algorithm diagram for motor speed control is shown in Fig. 5a, oil pump control and pump cycle in Fig. 5b, and temperature monitoring and control as shown in Fig. 5c. As indicated in Table 4, link control data between the PLC and the control interface, monitor on WinCC and the Web using PLC Tags.

\section{Results and Discussion}

The PLC control program is written using the instruction ladder on TIA PORTAL V15. Establish connection between PLC and WinCC environment to build monitoring console using "Device Configuration" on TIA PORTAL. For the finding lubricating modes corresponding to the operating modes, the temperature was measured at the bearings must be displayed and collected over time as well as over temperature alarms and ready status warnings for spindle operation. From the structure diagram of the system (Fig. 3), a control cabinet for the thermal experimental device of vertical spindle bearings was successfully fabricated (Fig. 6a,b). The cabinet allows to control the spindle speed through the rotation value set on the control interface. This cabinet allows to turn on and off the oil pump, compressed air source by relay, read the value from the analog sensor and then display it on the temperature meter and generate an alarm. It also allows connection to a computer for monitoring control via WinCC or remote web interface.

The reference thermometers used to calibrate the temperature sensor are the EXTECH 42560 infrared thermometer and ambient thermometer (Fig. 6c). After calibration, the sensor is mounted and fixed on the spindle housing. At the sensor mounting position, there is an insulated pipe between the sensor body and the spindle housing.

The control and monitoring screen interface include the functions of inputting the spindle speed value for the operation, turning on/off the oil pump and the compressed air source, cycling the pumping time, displaying real-time temperature values, doing statistics of values, entering the heat limit values on the bearings, doing alarms and graphing the bearing temperatures over time. That interface and its functions on WinCC with PLC control program as shown in Fig. 7.

Table 4. PLC Tags and control, monitoring functions

\begin{tabular}{|c|c|}
\hline PLC Tags & Function \\
\hline :="Tocdotrucchinh": & Spindle speed \\
\hline :="apsdau": & Oil pressure \\
\hline :="apskhi": & Air pressure \\
\hline :="nhietobil": & $\begin{array}{l}\text { Actual temperature at } \\
\text { bearing } 1\end{array}$ \\
\hline :="nhietobi2": & $\begin{array}{l}\text { Actual temperature at } \\
\text { bearing } 2\end{array}$ \\
\hline :="nhietobi3": & $\begin{array}{l}\text { Actual temperature at } \\
\text { bearing } 3\end{array}$ \\
\hline :="nhietobi4": & $\begin{array}{l}\text { Actual temperature at } \\
\text { bearing } 4\end{array}$ \\
\hline :="gioihant1": & $\begin{array}{l}\text { Limit temperature at } \\
\text { bearing } 1\end{array}$ \\
\hline$:="$ gioihant $2 ":$ & $\begin{array}{l}\text { Limit temperature at } \\
\text { bearing } 2\end{array}$ \\
\hline$=$ "gioihant $3 "$ : & $\begin{array}{l}\text { Limit temperature at } \\
\text { bearing } 3\end{array}$ \\
\hline :="gioihant4": & $\begin{array}{l}\text { Limit temperature at } \\
\text { bearing } 4\end{array}$ \\
\hline :="trangthaidongco": & Motor status \\
\hline :="Batbomdau": & Oil pump \\
\hline :="Tatbomdau": & Turn off the oil pump \\
\hline :="Autodau": & Auto mode of oil pump \\
\hline$:="{ }^{\prime}$ ton": & Pumpping time for oil \\
\hline$:=" t o f f ":$ & Off time of oil pump \\
\hline :="Batmaynenkhi ": & Turn on the air compressor \\
\hline :="Tatmaynenkhi": & Turn off the air compressor \\
\hline
\end{tabular}

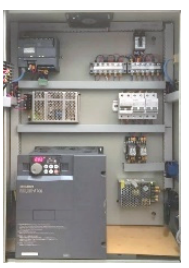

(a)

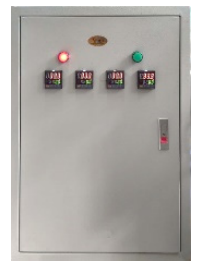

(b)

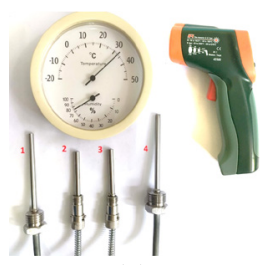

(c)
Fig. 6. Control cabinet and calibration devices for temperature sensors 
This interface is designed in the form of popups, each device will be controlled in its own control dialog, making the interface compact and easy to use (Fig. 7a). The temperature at the bearings measured by the sensor is displayed in the heat meter dialog box and is graphed continuously in real time that support the supervisor to update quickly and accurately (Fig. 7b,c). The measured temperature data will be stored and tabulated. It can be exported to the file formats such as excel, pdf to serve for calculation, data processing, reporting (Fig. 7d). The warnings will be issued whenever the heat value exceeds the limit as shown in Fig. 7e.

Besides, from the PLC Tags system as shown in Table 4, a remote monitoring interface via the internet is built with functions as shown in Fig. 8. HMI Web is designed based on HTML5 language combined with CSS, Javasccript, AWP, Ajax technology, etc. integrated with the Siemens' security [7]. That enables user monitoring and control spindle speed, cooling lubrication mode, temperature monitoring at spindle bearings, setting system control parameters, combination of alarm modes and displaying graphs with real-time data. The system can be accessed remotely by devices via a web browser.

The program connects and retrieves data between PLC and HMI on based a web of Siemens by PLC Tags of registers to be written in AWP language combined with data storage file in .xml, Ajax technology and Javascript language.

The scan frequency is $0.2 \mathrm{~s}$, this value allows displaying the current value status of the PLC register within $0.2 \mathrm{~s}$. The value of the PLC register is updated to the web HMI according to the control and monitoring status with a scan frequency of $0.5 \mathrm{~s}$. Actual latency is also related to many factors, the most important of which is the speed of the internet connection. If the internet connection speed is high and stable, the system can meet the control and monitoring requirements quickly and promptly.

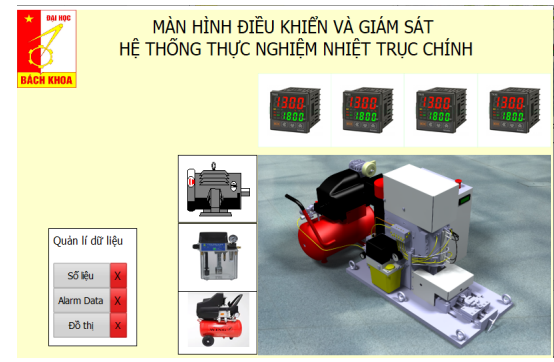

(a) Control interface on WinCC

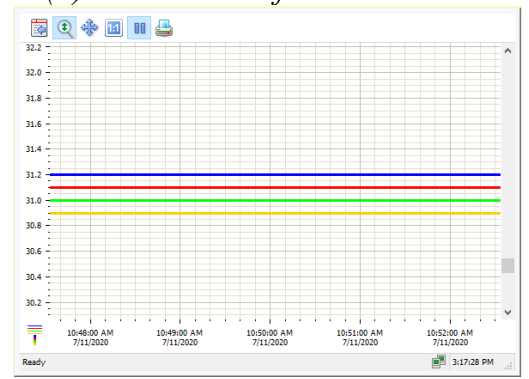

(c) Real time graphs of bearing heat

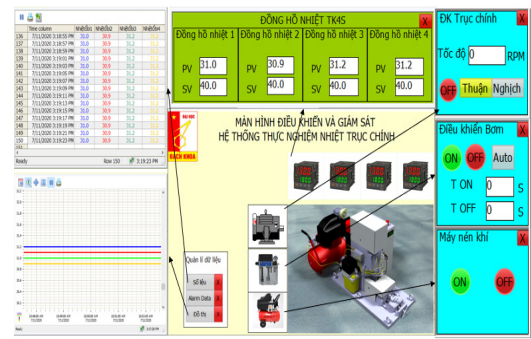

(b) Control dialogs for each device

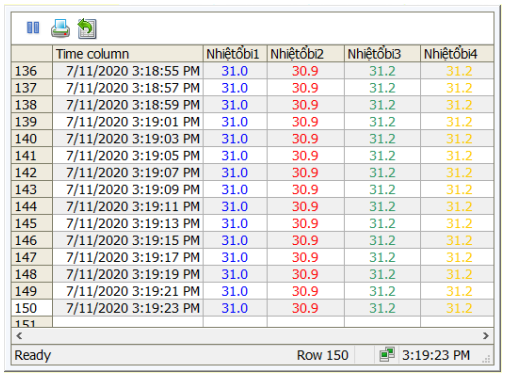

(d) Thermal statistics at each bearing

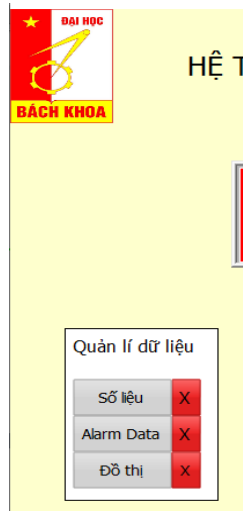

MÀN HİNH ĐIỀU KHIỂN VÀ GIÁM SÁT HỆ THÕNG THỰC NGHIỆM NHIẸT TRỤC CHÍNH

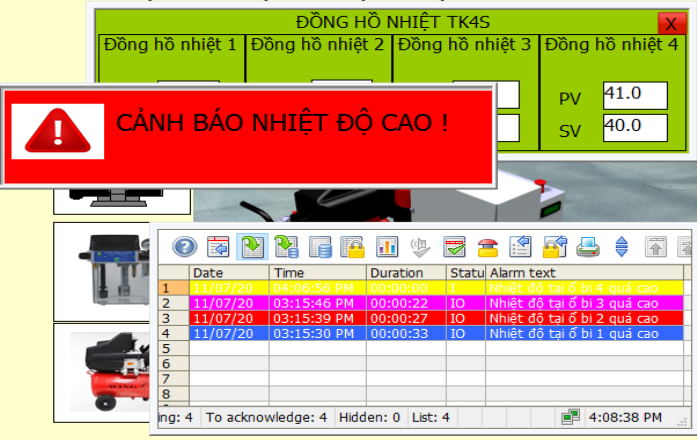

(e) Alarm mode and alarm data

Fig. 7. Control interface and On-site monitoring with functions on WinCC 


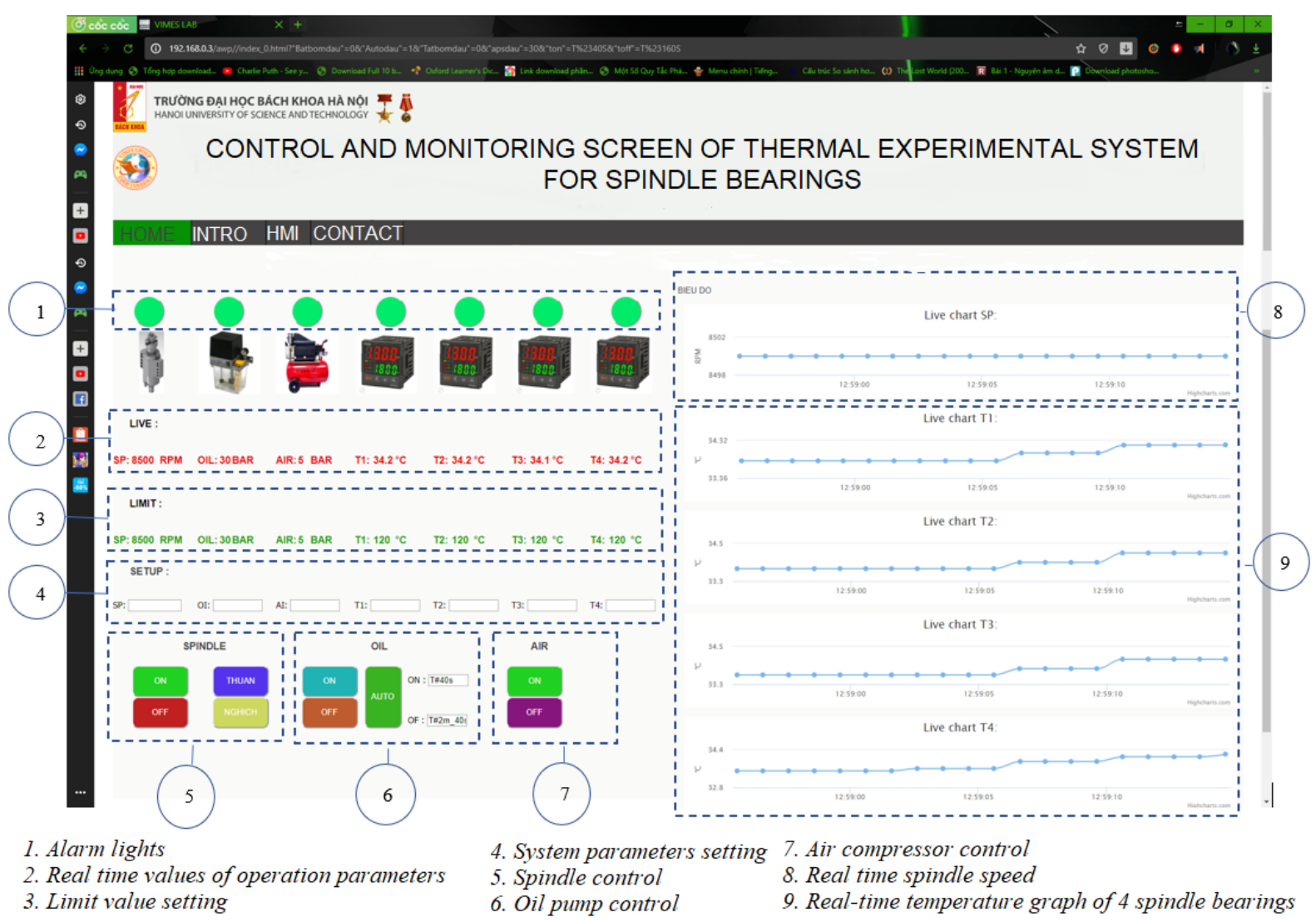

Fig. 8. Remote monitoring and control interface via the internet

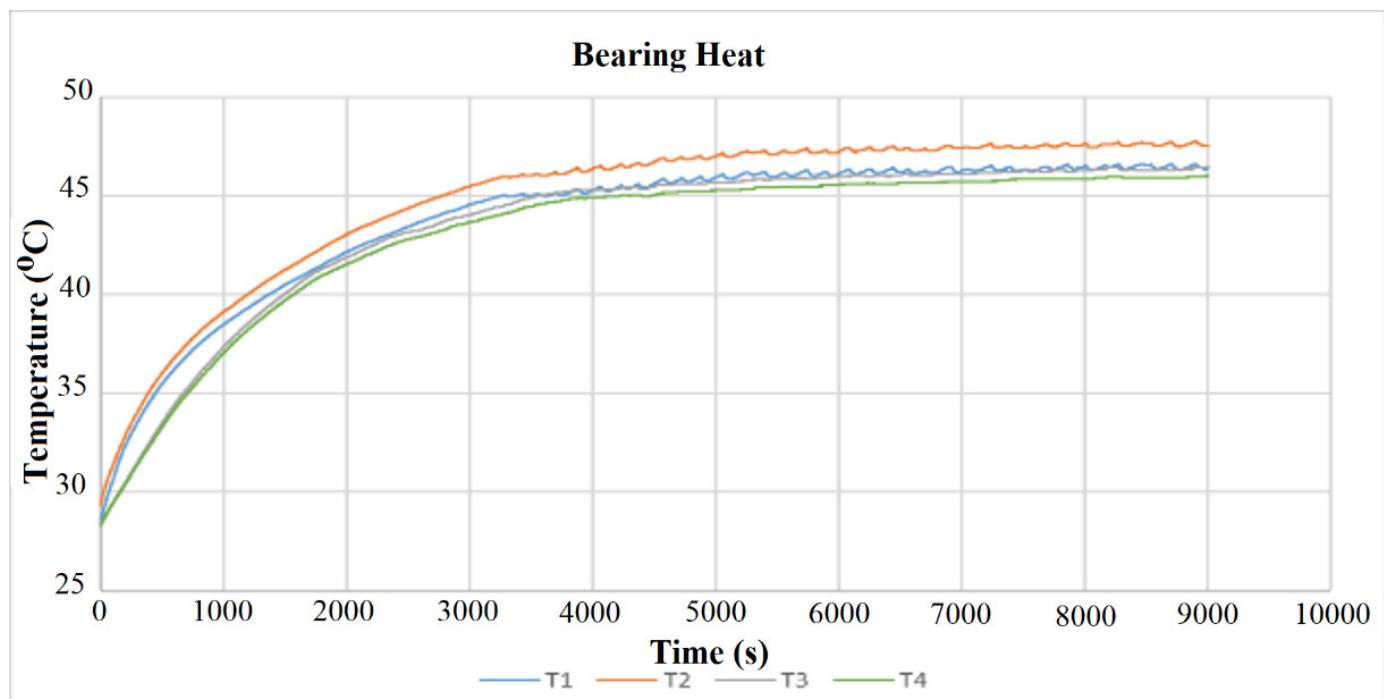

Fig. 9. Temperature experimental data of four spindle bearings over time T1(CB1), T2(CB2), T3(CB3), T4(CB4) at experimental mode with spindle speed $n=7800(\mathrm{rpm})$, ambient temperature $28^{\circ} \mathrm{C}$.

The measured temperature data will be stored and tabulated and can be exported to files such as excel, pdf, ... as shown in Fig. 9 to serve the calculation and data processing. The above monitoring control and data acquisition solution serves for monitoring control for thermal experimental equipment of spindle bearings and can be applied in automatic monitoring control for other industrial equipment to meet the needs of Industry 4.0 .

\section{Conclusion}

A design and manufacturing of a measuring, control, and monitoring system for spindle bearing thermal experimental equipment has been demonstrated in the research. Local monitoring control using WinCC with PC interface through TIA 
PORTAL software. The PLC S7-1200's Webserver function is used to control and monitor remotely. Both functions of the system allow users to real-time monitoring control. Thereby, the user can collect data on spindle speed, pump cycle, oil pump status, air source as well as temperature at the four spindle bearings. In which the system was integrated overtemperature, over-speed, and pressure warning. This system also allows the user to do experiments with the operating modes of each industrial oil and export the report data. This solution includes control and monitoring of power sources, monitoring of sensors, alarms and reporting locally or remotely. It can be applied to other industrial equipment to meet the needs of industry 4.0 in the connection of things.

\section{Acknowledgments}

This research is supported by the Hanoi University of Science and Technology's grassroots program T2018-PC-030. The authors would like to thank VIMES LAB for aiding them with their research

\section{References}

[1]. Giang-Nam Le, Vinh-Hai Nguyen, Tien-Thanh Le, A method to evaluate the effects of heat on a spindle of a CNC milling machine, International Research Journal of Advanced Engineering and Science, pp. 214-217, 2019

[2]. Giang Nam Le, Vinh Hai Nguyen, Thanh-Hai Thi Tran, Evaluation of the air-oil mixture in the mixing tube for lubrication of $\mathrm{CNC}$ machine tool's spindle bearings (original text in Vietnamese), in The 4th National Conference on Mechanical Science and Technology, vol. 2, pp. 743-749, Ho Chi Minh, 2015.

[3]. Mang, Theo, Encyclopedia of Lubricants and Lubrication, Verlag Berlin Heidelberg: Springer, 2014.

https://doi.org/10.1007/978-3-642-22647-2

[4]. Giang-Nam Le, Vinh-Hai Nguyen, Dinh-Thinh Vuong, Selection lubrication divice for vertical high speed spindle (original text in Vietnamese), Vietnam Mechanical Engineering Journal, vol. 7, pp. 33-41, 2020.

https://doi.org/10.1109/ICST.2008.45

[5]. Siemens AG, Simatic S7-1200 Programmable Controller, Siemens, Nürnberg, Germany Sep. 16, 2016. [Online]. Available:

https://support.industry.siemens.com/cs/document/10 9741593/simatic-s7-s7-1200-programmablecontroller?dti $=0 \& 1 \mathrm{c}=\mathrm{en}-\mathrm{WW}$

[6]. Siemens, Creating user-defined web pages for S71200/S7-1500 Simatic Step 7 (TIA Portal V16) S71200/S7-1500, Siemens AG, Nürnberg, Germany July. 4, 2020. [Online]. Available: https://support.industry.siemens.com/cs/document/68 011496/creating-and-using-user-defined-web-pageson-s7-1200-s7-1500?dti=0\&lc=en-WW

[7]. Siemens, Basics on creating HTMLs for SIMATIC CPUs, Siemens AG, Nürnberg, Germany Feb. 24, 2014. [Online]. Available: https://support.industry.siemens.com/cs/attachments/6 8011496/68011496_HTML_Basics_for_SIMATIC_C PUs_en.pdf 